\title{
Frequency of drug resistant Salmonella spp. isolated from poultry samples in Bangladesh
}

\author{
Muhammad Ali Akond, ${ }^{1 *}$ Momena Shirin, ${ }^{2}$ Saidul Alam, ${ }^{1}$ S. M. R. Hassan, ${ }^{1}$ Md. Mahbubur Rahman ${ }^{3}$ and \\ Mozammel $\mathrm{Hoq}^{4}$ \\ ${ }^{\text {I} D e p a r t m e n t ~ o f ~ B o t a n y, ~ J a h a n g i r n a g a r ~ U n i v e r s i t y, ~ D h a k a-1342, ~ B a n g l a d e s h ; ~}{ }^{2}$ Institute of Public Health, Mohakhali, Dhaka-1212, \\ Bangladesh; ${ }^{3}$ Laboratory Sciences Division, icddr,b, Dhaka-1212, Bangladesh; ${ }^{4}$ Department of Microbiology, University of Dhaka, \\ Dhaka-1000, Bangladesh
}

Received 19 June 2012/Accepted 13 October 2012

\begin{abstract}
Present study was conducted to determine the levels of Salmonella spp. mediated contamination in samples collected from poultry and poultry environments in Bangladesh and to determine the antibiotic resistance trait in those pathogens. A total of $\mathbf{3 0 0}$ samples were collected from five different sources (cloacal swab, intestinal fluid, egg surface, hand wash of chicken handler and soil of chicken market) and $80(26.6 \%)$ samples were found to be contaminated with Salmonella spp. One hundred and fifty Salmonella strains were isolated among which, 91 were detected as $S$. enteriditis and 59 as $S$. typhimurium through morphological, biochemical and serological tests. Susceptibility of the isolates against 13 antimicrobials was tested, and resistance against chloramphenicol $(30 \mu \mathrm{g})$, erythromycin (15 $\mu \mathrm{g})$, ampicillin $(10 \mu \mathrm{g})$, riphampicin $(5 \mu \mathrm{g})$, cephalexin $(15 \mu \mathrm{g})$, cefixine $(5 \mu \mathrm{g})$, penicillin $(10 \mu \mathrm{g})$, tetracycline $(30 \mu \mathrm{g})$, norfloxacin $(10 \mu \mathrm{g})$, nalidixic acid $(30 \mu \mathrm{g})$ and ciprofloxacin $(10 \mu \mathrm{g})$ was found in $58 \%, 82 \%, 88 \%, 60 \%, 65 \%, 50 \%, 100 \%, 100 \%, 20 \%, 20 \%$ and $20 \%$ of the strains, consecutively. $76 \%$ isolates were found to be sensitive against gentamicin and $70 \%$ against streptomycin. Some of the isolates interestingly exhibited multiple-drug resistances against at least 6 to 10 antibiotics. The results indicated the higher resistance of Salmonella spp. against antibiotics which serving as a threat not only to poultry industry of Bangladesh but also possesses a serious threat to public and animal health.
\end{abstract}

Key words: Salmonella spp.; drug resistance; poultry environments

Salmonella serotypes are significant zoonotic pathogens in both humans and animals (1) and cause a wide range of human diseases such as enteric fever, gastroenteritis and bacteremia (2). The worldwide annual estimation of the incidence of nontyphoidal salmonellosis is 1.3 billion and annual death is estimated to 3 million cases (3). Poultry and poultry products are imperative elements within the human food chain but they are widely accepted as an important reservoir of intestinal and food-born pathogen like Salmonella and recognized as vital sources of Salmonella infection in human $(4,5)$. Most cases of salmonellosis in human are the consequence of consuming contaminated poultry, pork, beef and eggs (6).

The exploitation of antimicrobial agents in any environment creates selective pressures that favor the endurance of antibiotic-resistant pathogens. The routine practice of antibiotic utilization to domestic animals as a means of preventing and treating diseases, as well as promoting growth, is an important factor in the

${ }^{\ddagger}$ Corresponding author. Mailing address: Muhammad Ali Akond, Department of Botany, Jahangirnagar University, Savar, Dhaka-1342, Bangladesh; E-mail: akond316@yahoo.com emergence of antibiotic-resistant bacteria that are consequently transferred to humans in the course of the food chain $(7,8)$.

In recent times, a significant increase in the occurrence of antimicrobial drug resistance in Salmonella strains is of great concern in both developed and developing countries (9-11). Furthermore, the wide spread use of antimicrobials in farm animals is often implicated in the emergence of multidrug-resistant strains of Salmonella (12). The bacterial resistance against antimicrobial agents is known to be driven by the interplay of several mechanistic and epidemiologic factors including the chromosomal defects, random mutation, plasmid exchange, and by the transfer of drug resistance genes by integron or transposon (1316). In different parts of the world, multi drug resistant strains of Salmonella are ubiquitous in poultry and poultry environments (17-18). There are reports of high prevalence of antibiotic resistant Salmonella isolates in Bangladesh (19).

Contaminated poultry products are among the most important sources for food-borne outbreaks in humans and Salmonella are isolated more often from poultry and poultry products than from any other animal food products (20-23). Like in many other developing countries, the hygiene practice of raw poultry and poultry products, and 
epidemiological study of antimicrobial resistance are in their infancy in Bangladesh. In addition, the lack of rigorous controls on antimicrobial usage, particularly in farm animal production system increases the risk of pathogenic microbes harboring an array of resistance gene. Therefore, this study was focused on the determination of the level of Salmonella contamination in the poultry environments and their resistance against different antibiotics in Bangladesh.

\section{MATERIALS AND METHODS}

Sampling Area and Sample Collection. The study was carried out during the period from October, 2008 to June, 2010. Three hundred samples from cloacal swabs of chicken $(n=80)$, intestinal fluid of chicken $(n=70)$, egg surface $(n=60)$, soil of chicken market $(n=40)$ and hand wash of chicken handlers $(n=50)$ were collected from various poultry shops of 4 City Corporation markets viz., Mohakhali, Dhaka New Market, Mirpur and Malibag of the Dhaka metropolitan city. The samples were collected following the procedure as stated by Akond et al., 2009 (24).

Transportation of Sample. All the samples were transported to the laboratory immediately after collection in an insulating foam box with ice maintaining the temperature ranging from $4{ }^{\circ} \mathrm{C}$ to $6{ }^{\circ} \mathrm{C}$. In case of the cloacal swab samples, the test tubes containing selenite broth were incubated for 6 hours at $37^{\circ} \mathrm{C}$ immediately after coming to the laboratory for the enrichment of the Salmonella spp.

Isolation of Salmonella spp. Serial dilutions up to $10^{-3}$ were made for soil sample. $0.1 \mathrm{ml}$ of sample from intestinal fluid, $0.2 \mathrm{ml}$ of sample prepared from soil of chicken market (dilution up to $10^{-3}$ ) and a loopfull of selective selenite broth from previously incubated cloacal swab sample were spread on the solid surface of Salmonella-Shigella (SS) agar medium (Hi-Media, India). A total of $1.0 \mathrm{ml}$ sample from intestinal fluid and soil of chicken market was placed onto sterile plates which was then mixed with sterile medium poured into the plates after being cooled to about $42-45^{\circ} \mathrm{C}$. About $10-100 \mathrm{ml}$ of water sample from egg surface and hand wash of chicken handlers was filtrated through the membrane filter $(0.45 \mu \mathrm{m}$, Millipore) to isolate the organism. The membrane filter was then placed on the surface of Salmonella-Shigella (SS) agar medium. Replications of all samples using triplicate plates were tested for successful isolation of typical colonies by incubating them at $37^{\circ} \mathrm{C}$ for 24 hours.

Biochemical Identification and Serotyping of Salmonella spp. A total of 150 strains were subjected for biochemical identification including Gram staining, urease test, catalase test, oxidase test, $\mathrm{H}_{2} \mathrm{~S}$ production test, lactose utilization test, indole test, Voges-Proskauer test and citrate utilization test according to Buchanan and Gibbons, 1974 (25). Moreover, Salmonella serotyping was determined by latex agglutination tests using polyvalent antisera (Denka Seiken Co. Ltd, Tokyo, Japan), according to the manufacturer's instruction. The presumptive Salmonella isolates were mixed with the latex test reagent and was observed for the agglutination reaction to check the presence of Salmonella.

Antimicrobial Susceptibility Test. A total of 100 selected Salmonella strains, recovered from cloacal swab, intestinal fluid, handwash of chicken handler, egg surface and soil sample from chicken market, were tested for resistance against antimicrobial agents by Kirby-Bauer method (26) using Mueller-Hinton agar plates. The standard procedure of the Clinical and Laboratory Standards Institute (CLSI) (27) were strictly followed throughout the testing procedure. Quality control strain Escherichia coli ATCC 25922 was included in each run. All Salmonella isolates were subjected against 14 commercial antibiotic discs (Becton Dickinson Antibiotic Disc, U.S.A.) of streptomycin $(10 \mu \mathrm{g})$, erythromycin $(15 \mu \mathrm{g})$, chloramphenicol $(30 \mu \mathrm{g})$, ciprofloxacin $(10 \mu \mathrm{g})$, tetracycline $(30 \mu \mathrm{g})$, penicillin $(10 \mu \mathrm{g})$, norfloxacin $(10$ $\mu \mathrm{g})$, cephalexin $(15 \mu \mathrm{g})$, riphampicin $(5 \mu \mathrm{g})$, cefixine $(5 \mu \mathrm{g})$, ampicillin $(10 \mu \mathrm{g})$, nalidixic acid $(30 \mu \mathrm{g})$ and gentamicin $(10 \mu \mathrm{g})$. The isolates were categorized as susceptible, intermediate and resistant according to the zone diameter interpretative standards recommendations by CLSI (27).

\section{RESULTS}

Frequency of Salmonella isolates from different samples. Out of 300 poultry samples, $80(26.6 \%)$ were found to be contaminated with Salmonella spp. as determined from several biochemical and serological tests (Tables 1 \& 2). Higher proportion of Salmonella contamination were found in the intestinal fluid samples (60\%). $23.3 \%$ of the cloacal swab samples found to harbor Salmonella spp. Relatively lower frequency of Salmonella contamination were found on the egg surface (13.3\%), soil of chicken market $(15 \%)$ and hand wash of chicken handler $(6 \%)$ samples (Table 1).

TABLE 1. Frequency of Salmonella spp. in various poultry samples

\begin{tabular}{|c|c|c|c|c|c|}
\hline \multirow[t]{2}{*}{$\begin{array}{l}\text { Type of } \\
\text { samples }\end{array}$} & \multirow{2}{*}{$\begin{array}{c}\text { No. of } \\
\text { Samples } \\
\text { Tested }\end{array}$} & \multirow{2}{*}{$\begin{array}{c}\text { No. of } \\
\text { Samples } \\
\text { Positive } \\
(\%)\end{array}$} & \multirow{2}{*}{$\begin{array}{l}\text { Total no. } \\
\text { of isolated } \\
\text { Salmonella } \\
\text { strains }\end{array}$} & \multicolumn{2}{|c|}{$\begin{array}{c}\text { Type of Salmonella } \\
\text { species }(\mathrm{n}=150)\end{array}$} \\
\hline & & & & $\begin{array}{c}S . \\
\text { enteriditis } \\
(\%)\end{array}$ & $\begin{array}{c}S \\
\text { typhimurium } \\
(\%)\end{array}$ \\
\hline $\begin{array}{l}\text { Cloacal } \\
\text { swab }\end{array}$ & 80 & $\begin{array}{c}21 \\
(26.3)\end{array}$ & 51 & $32(62.8)$ & $19(37.2)$ \\
\hline $\begin{array}{l}\text { Intestinal } \\
\text { fluid }\end{array}$ & 70 & $42(60)$ & 74 & $43(58.1)$ & $31(42.9)$ \\
\hline $\begin{array}{l}\text { Egg } \\
\text { surface }\end{array}$ & 60 & 8 (13.3) & 12 & $8(66.7)$ & $4(33.3)$ \\
\hline $\begin{array}{l}\text { Hand } \\
\text { wash of } \\
\text { chicken } \\
\text { handler }\end{array}$ & 50 & $3(6)$ & 5 & $3(60)$ & $2(40)$ \\
\hline $\begin{array}{l}\text { Soil of } \\
\text { chicken } \\
\text { market }\end{array}$ & 40 & $6(15)$ & 8 & $5(62.5)$ & $3(37.5)$ \\
\hline Total & 300 & $\begin{array}{c}80 \\
(26.6)\end{array}$ & 150 & $91(60.7)$ & $59(39.3)$ \\
\hline
\end{tabular}

TABLE 2. Morphological and biochemical identification of Salmonella strains

\begin{tabular}{ccc}
\hline Test & Salmonella spp. & \% Salmonella isolates \\
\hline Gram Staining & Gram negative, & 99 \\
Urease & Small & 80 \\
Indole production & - & 75 \\
Catalase & - & 90 \\
Voges-Proskauer & - & 80 \\
H 2 S production & + & 90 \\
Oxidase & + & 90 \\
Lactose fermentation & - & 90 \\
Citrate utilization & + & 80 \\
\hline$+=$ Positive; - = Negative; BCTC & & Black Centered Transparent Colony
\end{tabular}

Among 150 Salmonella isolates, $91(60.7 \%)$ were identified as S. enteriditis. Rests of the isolates (39.3\%) were detected as S. typhimurium. S. enteriditis was the predominant species in all the tested samples and it was found more frequently in the egg surface samples (66.7\%). Whereas, intestinal fluid samples showed 
TABLE 3. Antimicrobial drug resistance pattern of the Salmonella isolates

\begin{tabular}{lcccccc}
\hline & \multicolumn{5}{c}{ Antibiotic susceptibility/resistance pattern } \\
\cline { 2 - 7 } Antibiotic Discs & \multicolumn{2}{c}{ Resistant } & Intermediate & Sensitive \\
\cline { 2 - 7 } & $\%$ isolates & $\begin{array}{c}\text { Inhibition } \\
\text { zone }(\mathrm{mm})\end{array}$ & $\begin{array}{c}\text { \% isolates } \\
\text { Chloramphenicol }(30 \mu \mathrm{g})\end{array}$ & $\begin{array}{c}\text { Inhibition } \\
\text { zone }(\mathrm{mm})\end{array}$ & $\%$ isolates & $\begin{array}{c}\text { Inhibition } \\
\text { zone }(\mathrm{mm})\end{array}$ \\
Erythromycin $(15 \mu \mathrm{g})$ & 58 & $<12$ & 25 & $13-17$ & 17 & $>18$ \\
Ampicillin $(10 \mu \mathrm{g})$ & 82 & $<13$ & 18 & $14-22$ & 0 & $>23$ \\
Gentamicin $(10 \mu \mathrm{g})$ & 88 & $<13$ & 12 & $14-16$ & 0 & $>17$ \\
Riphampicin $(5 \mu \mathrm{g})$ & 0 & $<12$ & 24 & $13-14$ & 76 & $>15$ \\
Cephalexin $(15 \mu \mathrm{g})$ & 60 & $<16$ & 24 & $17-19$ & 16 & $>20$ \\
Cefixine $(5 \mu \mathrm{g})$ & 65 & $<15$ & 15 & $16-20$ & 20 & $>21$ \\
Penicillin $(10 \mu \mathrm{g})$ & 50 & $<15$ & 20 & $16-18$ & 30 & $>19$ \\
Tetracycline $(30 \mu \mathrm{g})$ & 100 & $<28$ & 0 & $\mathrm{NA}$ & 0 & $>29$ \\
Streptomycin $(10 \mu \mathrm{g})$ & 100 & $<14$ & 0 & $15-18$ & 0 & $>19$ \\
Norfloxacin $(10 \mu \mathrm{g})$ & 0 & $<13$ & 30 & $14-17$ & 70 & $>18$ \\
Ciprofloxacin $(5 \mu \mathrm{g})$ & 20 & $<12$ & 25 & $13-16$ & 55 & $>17$ \\
Nalidixic acid $(30 \mu \mathrm{g})$ & 20 & $<15$ & 15 & $16-20$ & 65 & $>21$ \\
\hline
\end{tabular}

relatively higher frequency $(42.9 \%)$ for S. typhimurium than the other samples.

Antibiogram of the isolates. All the Salmonella isolates showed resistance against penicillin and tetracycline (Table 3). Higher resistance was observed against ampicillin (88\%), erythromycin (82\%), cephalexin $(65 \%)$, riphampicin $(60 \%)$, chloramphenicol $(58 \%)$ and cefixine $(50 \%)$. The isolates showed lower resistance $(20 \%)$ against norfloxacin, ciprofloxacin and nalidixic acid. No isolate was found to be resistant against gentamicin and streptomycin (Table 3 ).

\section{DISCUSSION}

The present study demonstrated a considerable high frequency $(26.6 \%)$ of contamination in poultry samples with Salmonella spp. Therefore, poultry seems to be one of the main reservoirs of Salmonella spp. in Bangladesh. The high level of contamination indicates an alarming situation, both for chicken farming and public health as well. A similar rate $(25 \%)$ of Salmonella spp. contamination in the samples from poultry and poultry environments has been evident by Hassan, 2004 in Bangladesh (28). That study also reported that $25 \%$ of the cloacal swab samples and $50 \%$ of intestinal fluid samples were contaminated with Salmonella spp. In this study, we found Salmonella contamination in $26 \%$ and $60 \%$ of cloacal swab and intestinal fluid samples, respectively. The occurance of Salmonella contamination in samples from poultry sources has also been reported from various parts of the world; $17 \%, 35 \%, 36 \%, 39 \%$, and $53 \%$ in USA, Spain, Korea, Brazil and Vietnam, consequtively (29-33). The presence of Salmonella spp. in the hand wash samples of chicken handler indicated a potential breakdown of personal hygiene at the stage of chicken handling and processing.

Studies have demonstrated that poultry feeds have been implicated as an important source of Salmonella spp. (34) and may therefore be the consequence of the subsequent contamination of eggs. However, egg surface might have been contaminated with Salmonella spp. with feces during lay in unhygienic condition or from infected poultry. Among the animal protein ingredients, a major ingredient of poultry feeds, locally processed cheap fish wastes were found to be a vital cause for bacterial contamination of poultry feeds (18). Moreover, Salmonella was reported as a common microflora in animal feedstuffs, raw feeding materials and poultry feeds (34). Careless and unhygienic handling process serves as a frequent source of contamination with Salmonella in pre-stuffed chickens in poultry shops. Poultry and poultry products like eggs and plastic-wrapped poultry meat found in various super shops and ready-to-eat foods become cross contaminated with Salmonella spp.and other pathogenic bacteria from food handlers with poor personal hygiene and may be from other raw poultry products.

In addition, our study confirmed a high incidence of antibiotic resistance with the frequency of $20 \%$ to $100 \%$ among Salmonella spp. isolated from poultry and poultry environments in Bangladesh. In present study, Salmonella strains isolated from poultry sources were commonly resistant against ampicilin, tetracycline and chloramphenicol and susceptible to nalidixic acid and gentamicin as found in several studies in Bangladesh (28, 32, 33, 35-37). However, resistance against gentamicin and streptomycin was absent in all strains and comparatively lower resistance was observed against 
norfloxacin, nalidixic acid and ciprofloxacin. Resistance against penicilin, ampicilin, tetracycline and erythromycin was often observed due to low cost, ready availability and for drug abuse (33). Therefore, prudent use of antimicrobials in animal production system has been accepted worldwide as a means of preventing development of the antimicrobial resistance in pathogenic bacteria (38). Moreover, all the isolates exhibited multidrug resistance against more than five antibiotics. Similar findings on multidrug resistance among Salmonella strains have been reported from Bangladesh and various parts of the world (18, 28, 3537).

The ability of bacteria to acquire antibiotic resistance gene and subsequently spread them to many different bacterial species is now well known. Integrons play an important part in the transfer of resistance among Salmonella serotypes to a variety of antimicrobial drugs (37, 39). Several surveys on antibiotic operation in Bangladesh have revealed that peoples are in the habit of consuming antibiotics familiarized in frequent uptake of antibiotics than necessary (28) and antibiotics can be bought here easily from drugstores without any prescription. It may facilitate the development of multidrug resistant pathogens, as regular exploit of antimicrobials would put selective pressure for development and proliferation of resistance genes. In addition, low cost and available antimicrobials like ampicillin, penicillin, tetracycline and erythromycin are frequently used as growth promoters or feed additives or preservatives to the food producing animals and poultry flocks to assuage the escalating food requirements for the augmented population in Bangladesh.

The results of the study have illustrated the extent of antibiotic resistance in Salmonella serotypes from poultry sources in Bangladesh. The domestic and commercial handlers of poultry and poultry products in chicken shops and household and the peoples engaged in the poultry farms need more attention to strictly follow the rules and guidelines of hygiene to reduce or eliminate the risk of antibiotic resistant Salmonella and other pathogenic microbes. In addition, the use of antibiotics both for farming and for medication should be astute to minimize the chance for organisms to develop resistance.

\section{REFERENCES}

1. Winokur, P. L., et al. 2000. Animal and human multidrug-resistant, cephalosporin-resistant Salmonella isolates expressing a plasmidmediated CMY-2 AmpC beta-lactamase. Antimicrobial Agents of Chemotherapy 44: $2777-2783$

2. Bennasar, A., G. Luna, B. Cabrer, and J. Lalucat. 2000. Rapid identification of Salmonella typhimurium, S. enteritidis and S. virchow isolates by polymerase chain reaction based fingerprinting methods. Int. Microbiol 3: 31-38.

3. Tassios, P. T., et al. 1997. Molecular epidemiology of antibiotic resistance of Salmonella enteritidis during a 7-year period in Greece. J Clin Microbiol 35: 1316-1321.
4. Limawongpranee, S., et al. 1999. Prevalence and persistence of Salmonella in broiler chickens flocks. J. Vet. Medical Sci. 61 (3): 255-259.

5. EFSA (European Food Standards Agency). 2004. Available at: www.efsa.eu.int/science/biohaz / biohaz_opinions/723 en.htm

6. Gomez, T. M., et al. 1997. Food borne Salmonellosis. World Health Stat Q 50: $81-90$.

7. Tollefson, L., S. F. Altekruse, and M. E. Potter. 1997. Therapeutic antibiotics in animal feeds and antibiotic resistance. Rev Sci Tech 16: 709715

8. Witte, W. 1998. Medical consequences of antibiotic use in agriculture. Science 279: 996-997

9. Threlfall, E. J. 2002. Antimicrobial drug resistance in Salmonella: problems and perspectives in food andwater-borne infections. FEEMS Microbiol. Rev 26: $141-148$.

10. Van, D. E., W. J. Wannet, D. J. Houwers, and W. Van Pelt. 2003. Antimicrobial susceptibilities of Salmonella strains isolated from humans, cattle, pigs, and chickens in the Netherlands from 1984 to 2001. J. Clin. Microbiol. 41: 3574-8.

11. Cailhol, J., et al. 2006. Trends in antimicrobial resistance phenotypes in nontyphoid salmonellae from human and poultry origins in France. Epidemiol Infect 134: 171180.

12. Schroeder, C. M., et al. 2002. Antimicrobial resistance of Escherichia coli 0157:H7 isolated from humans, cattle, swine and food. Appl. Environmental Microbiol 68: 576-581.

13. Canton, R. 2008. Antibiotic resistance genes from the environment: A perspective through newly identified antibiotic resistance mechanisms in clinical setting. European Soc Clin Microbiol Infect Dis 15: 20-25.

14. Hung, D. T. and B. B. Kaufman. 2010. The Fast Track to Multidrug Resistance. Mol Cell 37: 297-298.

15. Ochiai, K., T. Yamanaka, K. Kimura, and O. Sawada. 1959. Inheritance of drug resistance (and its transfer) between Shigella strains and Between Shigella and E. coli strains. Hihon Iji Shimpor 34: 1861

16. Bennett, P. M. 2008 Plasmid encoded antibiotic resistance: Acquisition and transfer of antibiotic resistance genes in bacteria. Br J Pharmacol 153: 347 357.

17. Alambedji, R. B., A. Fofana, M. Seydi, and A. J. Akakpo. 2006. Antimicrobial Resistance of Salmonella isolated from poultry carcasses in Dakar (Senegal). Braz J Microbiol 37 (4): 57-61.

18. Okoli, I. C., G. E. Endujihe, and I. P. Ogbuewu. 2006. Frequency of isolation of Salmonella from commercial poultry feeds and their antimicrobial resistance profiles, Imo State, Nigeria. Online J. Health and Allied Sci. 5 (2): 3.

19. Khan, M. F. R., et al. 2005. Antibiogram and plasmid profile analysis of isolated poultry salmonella of Bangladesh. Pak J Bio Sci 8: 1614-1619.

20. Braden, C. R. 2006. Salmonella enterica serotype Enteritidis and eggs: A national epidemic in the United States. Clin Infect Dis 43: 512-517.

21. Habtamu, T. M., R. Rathore, K. Dhama and R. K. Agarwal. 2011. Isolation, Identification and Polymerase Chain Reaction (PCR) Detection of Salmonella species from field materials of poultry origin. Int J Microbiol Res 2: $135-142$.

22. Kabir, S. M. L. 2010. Avian colibacillosis and salmonellosis: A closer look at epidemiology, pathogenesis, diagnosis, control and public health concerns. Int. J. Environ. Res. Public Health 7: 89-114.

23. Linam, W. M. and M. A. Gerber. 2007. Changing epidemiology and prevention of salmonella infections. Pediatric Infect Dis J 26: 747-748.

24. Akond, M. A., A. Saidul, S. M. R. Hasan, and S. Momena. 2009 Distribution of Vibrio Cholerae and its Antibiotic Resistance in the Samples from Poultry and Poultry Environment of Bangladesh. Advances in Environ. Biol 3 (1): 25-32.

25. Buchanan, R. E. and N. E. Gibbons. 1974. Bergey's manual of determinative Bacteriology, 8th Ed. The Williams and Wilkins, Baltimore.

26. Bauer, A. W., W. M. Kirby, J. C. Sherris, and M. Turck. 1966. Antibiotic susceptibility testing by a standardized single disk method. American J Clinical Pathology 45 (4): 493-496.

27. CLSI (Clinical and Laboratory Standards Institute). 2005. Performance standards for antimicrobial susceptibility testing; 15th informational supplement, CLSI/NCCLS M100-S15, Clinical and Laboratory Standards Institute, Wayne, PA.

28. Hasan, S. M. R. 2004. Antibiotic Resistance of Clinical and Environmental isolates of Salmonella spp. from Bangladesh. M.Sc. Thesis, Department of Botany, Jahangirnagar University. Savar, Dhaka, Bangladesh.

29. Logue, C. M., et al. 2003. The incidence of Antimicrobial-Resistant Salmonella spp. on Freshly Processed Poultry from US Midwestern Processing Plants. J. Appl. Microbiol. 94:16-24.

30. Dominguez, C., I. Gomez, and J. Zumalacarregui. 2002. Prevalence of Salmonella and Campylobacter in retail chicken meat in Spain. Int J Food Microbiol 72: 165-168.

31. Chung, Y. H., S. Y. Kim, and Y. H. Chang. 2003. Prevalence and antibiotic susceptibility of Salmonella isolated from foods in Korea from 1993 to 2001. J Food Prot 66: 1154-1157. 
32. Aldemir, R. R., et al. 2007. Salmonella spp. in raw broiler parts: occurrence, antimicrobial resistance profile and phage typing of the Salmonella enteritidis isolates. Brazilian J. Microbiol. 38: 296-299.

33. Van, T. T. H., et al. 2007. Detection of Salmonella spp. in Retail Raw Food Samples from Vietnam and Characterization of Their Antibiotic Resistance. Appl. Environ. Microbiol. 73 (21): 6885-6890

34. Jones, F. T. and K. E. Richardson. 2004. Salmonella in commercially manufactured feeds. Poultry Sciences 83: 384-391.

35. Sisak, F., et al. 2006. Antibiotic resistance of Salmonella spp. isolates from pigs in the Czech Republic. Veterinarni Medicina 51 (5): 303-310.
36. Mayrhofer, S., P. Paulsen, F. J. M. Smulders, and F. Hilbert. 2004 Antimicrobial resistance profile of five major food-borne pathogens isolated from beef, pork and poultry. Int. J Food Microbiol 97: 23-29.

37. David, G., et al. 2001. The Isolation of Antibiotic-Resistant Salmonella from Retail Ground Meats. The New Eng J Medicine 345 (16): 1147-1154.

38. WHO (World Health Organization). 1998. Use of quinolones in food animals and potential impact on human health. Report of a WHO meeting. WHO, Geneva, Switzland.

39. Hall, R. M. 1997. Mobile gene cassettes and integrons: moving antibiotic resistance genes in gram-negative bacteria. Ciba Found Symp 207: 192-202. 